\title{
24. DATA REPORT: CHARACTERIZATION OF DISTRIBUTIONS OF PHOTOSYNTHETIC PIGMENTS IN SAPROPELS FROM HOLES 966D AND 969C ${ }^{1}$
}

\author{
V. Cariou-Le Gall, ${ }^{2}$ A. Rosell-Mele, ${ }^{2}$ and J.R. Maxwell ${ }^{2}$
}

\begin{abstract}
The distribution of chlorins and carotenoids in 22 sapropel samples from Ocean Drilling Program Leg 160, Holes 966D and 969C, have been examined by combined liquid chromatography-mass spectrometry under atmospheric pressure ionization conditions. Up to 42 components were detected over the range of samples (including chlorophyllone $a$, pyrophaeophorbides, pyrophaeophytins, steryl chlorin esters $a$ and $b$, as well as carotenes). The samples showed two basic types of pigment distribution, with no obvious relationship between these distributions and the sedimentological parameters.
\end{abstract}

\section{INTRODUCTION}

According to a definition by Kidd et al. (1978)—although not generally accepted-sapropels correspond to open-marine sediment layers more than $1 \mathrm{~cm}$ thick with an organic carbon content of at least 2 $\mathrm{wt} \%$. In the present study, the distribution of photosynthetic pigments (chlorophyll derivatives as well as carotenoids) in 22 sapropel samples from the Eastern Mediterranean Sea (Ocean Drilling Program Leg 160, Sites 966 and 969) were examined by combined reversedphase liquid chromatography-mass spectrometry (LC-MS) under atmospheric pressure ionization (APCI) conditions, to obtain new clues about the origin and accumulation of such organic matter-rich sediments. Distributions of chlorins and carotenoids in sedimentary records are commonly used in paleoenvironmental studies to estimate the algal pigment diversity in phytoplanktonic populations, as well as to trace the fate of the organic matter during transport from the surface of the water column to the bottom sediment. Because sediments often exhibit a high pigment diversity (due mainly to the presence of numerous transformation products), chromatographic and spectrometric methods are required for pigment identification and quantification.

\section{EXPERIMENTAL}

\section{Sample Origin and Extraction}

Sediments were obtained from core sections of Holes 966D $\left(33^{\circ} 48^{\prime} \mathrm{N}, 32^{\circ} 42^{\prime} \mathrm{E} ; 940 \mathrm{~m}\right.$ water depth) and $969 \mathrm{C}\left(33^{\circ} 50^{\prime} \mathrm{N}\right.$, $24^{\circ} 53^{\prime} \mathrm{E}$; $220 \mathrm{~m}$ water depth), located in the Levantine Basin and on the Mediterranean Ridge, respectively. Samples originated from various depths of Hole 966D (Table 1) and from the uppermost sapropel layers of Hole 969C (Table 1). Sediment is Pleistocene (Core 160969C-1H and Core 160-966D-2H) to Pliocene (Cores 160-966D$5 \mathrm{H}$ through $8 \mathrm{H}$ ) in age.

Frozen sediment was freeze dried and the whole sample extracted in $10 \%$ aqueous acetone at $4^{\circ} \mathrm{C}$ for $24 \mathrm{hr}$ with constant mixing. Following centrifugation, the supernatant was filtered and the extract evaporated to dryness and dissolved in $100 \mu \mathrm{L} 10 \%$ aqueous acetone. The sapropels were generally dark grey to black, but the acetone extracts ranged in color from yellow to deep brown-green (Table 1).

${ }^{1}$ Robertson, A.H.F., Emeis, K.-C., Richter, C., and Camerlenghi, A. (Eds.), 1998. Proc. ODP, Sci. Results, 160: College Station, TX (Ocean Drilling Program).

${ }^{2}$ Organic Geochemistry Unit, School of Chemistry, University of Bristol, Cantock's Close, Bristol BS8 1TS, United Kingdom. j.r.maxwell@bris.ac.uk

\section{Liquid Chromatography-Mass Spectrophotometry}

Pigment analyses were carried out under high-performance liquid chromatography (HPLC) reversed-phase conditions using a $\mathrm{C}_{18}$ ODS $3 \mu \mathrm{m}$ Spherisorb column $(150 \mathrm{~mm} \times 4.6 \mathrm{~mm}$ i.d. $)$ with a $\mathrm{C}_{18}$ directconnect guard column. The HPLC instrument was operated at a flow rate of $1 \mathrm{~mL} \mathrm{~min}^{-1}$ using a linear gradient program (Table 2) that allowed the resolution of the more polar components in total unmethylated acetone extracts without addition of an ion-pairing reagent. Fil-

Table 1. Characteristics of sapropel samples from Holes 966D and 969C.

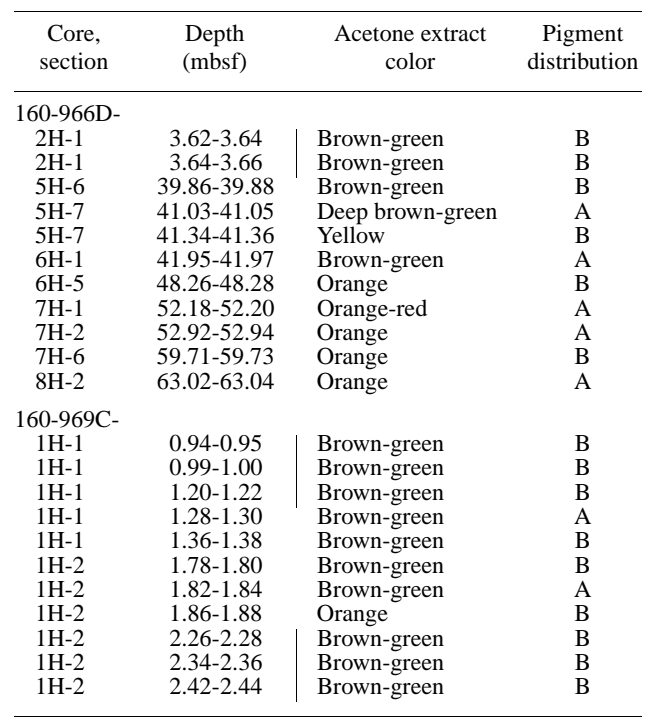

Note: Vertical bars indicate samples from the same sapropel layer.

Table 2. Solvent elution program for LC-MS, and typical back-pressures at a flow rate of $1 \mathrm{~mL} \mathrm{~min}{ }^{-1}$.

\begin{tabular}{rrrrr}
\hline $\begin{array}{c}\text { Time } \\
(\mathrm{min})\end{array}$ & $\begin{array}{c}\text { Methanol Acetone } \\
(\%)\end{array}$ & $\begin{array}{c}\text { Water } \\
(\%)\end{array}$ & $\begin{array}{c}\text { Pressure } \\
(\mathrm{psi})\end{array}$ \\
\hline 0 & 80 & 0 & 20 & $\sim 2700$ \\
15 & 60 & 30 & 10 & $\sim 1600$ \\
20 & 60 & 30 & 10 & $\sim 1600$ \\
30 & 30 & 60 & 10 & $\sim 1500$ \\
50 & 5 & 90 & 5 & $\sim 1000$ \\
65 & 5 & 90 & 5 & $\sim 1000$ \\
75 & 80 & 0 & 20 & $\sim 2700$ \\
& & & &
\end{tabular}


tered HPLC-grade solvents (Rathburn) and distilled water were used. Before entering the ion source, the elution mixture was passed through an on-line Waters 991 photodiode array detector for determination of the absorbance (UV-VIS) spectra of components (350-700 $\mathrm{nm})$ and monitoring the chromatographic separation $(\lambda=430 \mathrm{~nm})$. A wavelength of $430 \mathrm{~nm}$ rather than $400 \mathrm{~nm}$ was chosen to allow monitoring and detection of carotenoids as well as chlorins.

LC-MS was carried out using a Waters (Watford, UK) MS 600 Silk quaternary delivery HPLC-system, fitted with a Rheodyne 7125 injection valve (20- $\mu \mathrm{L}$ calibrated loop) and a Finnigan MAT (Hemel Hempstead, UK) TSQ 700 quadruple mass spectrometer, linked by a Finnigan MAT APCI interface. The interface conditions were: vaporizer temperature $550^{\circ} \mathrm{C}$, capillary temperature $300^{\circ} \mathrm{C}$, corona 5 $\mu \mathrm{A}$, sheath gas pressure $50 \mathrm{psi}$, and auxiliary gas pressure $20 \mathrm{psi}$. Mass spectra were obtained in the positive-ion mode, with scanning from $\mathrm{m} / \mathrm{z} 400$ to 1200 every $2 \mathrm{~s}$.

\section{RESULTS \\ Pigment Identification}

The UV-VIS chromatograms showed the presence of up to 42 significant peaks over the range of sapropel samples studied (Figs. 1-4; see Table 3 for pigment identification), although only certain peaks occurred systematically in all the acetone extracts, and the relative abundance of the pigments varied from one sample to another. No bacteriochlorophyll derivative or bacterial carotenoid could be identified. Although the presence of such pigments in some of the samples cannot be excluded, their abundances were not significant. Many peaks remain unidentified, but on the basis of their absorbance and mass spectra, the components can be classified into two categories: chlorophyll-derived chlorins and carotenoids.

\section{Chlorins}

Over the 22 samples, up to 14 and 5 components derived from chlorophyll $a(\mathrm{Chl} a)$ and chlorophyll $b(\mathrm{Chl} b)$ respectively, were identified. Chlorophyllone $a$ (peak 4), a Chl $a$ transformation product containing an additional exocyclic ring, was present in all samples and was generally dominant (Figs. 1-4). The identification of this pigment was confirmed by comparison of the retention time and spectra with those of an authentic standard. Chlorin identities revealed also the systematic occurrence of the classical "pyro-" counterparts of phaeophorbides $a$ and $b$, whereas the "pyro-" counterparts of the nonpolar phaeophytins $a$ and $b$ occurred only in certain samples. Eight other peaks corresponding to nonpolar chlorophyll derivatives were present in the samples containing the "pyro-" counterparts of the phaeophytins $a$ and $b$ and correspond to steryl chlorin esters (SCEs). Up to 10 SCE $a$ components were found (peaks 37-42; including coeluting components) and, more surprisingly, up to 2 SCE $b$ components were also detected (peaks 35 and 36). In the mass spectra of the SCEs, the protonated molecule indicates the presence of an esterifying alcohol on the pyrophaeophorbide nucleus and direct comparison with the spectra of pyrophaeophytin $a$ and pyrophaeophytin $b$ indicates that the common fragment at $\mathrm{m} / \mathrm{z}$ of 535 and 549, respectively, corresponds to loss of the esterifying side-chain as a sterene.

\section{Carotenoids}

Only certain of the many components apparent in the absorbance chromatograms were observed in the base peak ion chromatograms (Figs. 3B, 4B). On the basis of their absorbance spectral characteristics, most of those pigments correspond to carotenoids (Figs. 3B, 4B; Table 3). Comparison with the UV-VIS spectra and retention times of standards suggests the occurrence of zeaxanthin and canthaxanthin (peaks 12 and 17, respectively) in almost all the samples, as well as the nonspecific $\alpha$ - and $\beta$-carotenes (peaks 31 and 32, respectively) in some of the samples. The other carotenoids remain unidentified, because their spectral characteristics and retention time data did not match those of the standards available or those of the most typical microalgal pigments. This may suggest that most of the compounds correspond to transformation products.

Further studies (data not shown) revealed that the LC/APCI-MS conditions employed are not suitable for the identification of many carotenoids, especially the carotenes and other components whose mass spectra contained large numbers of ions with only low $\mathrm{m} / \mathrm{z}$ values.

\section{Pigment Distributions}

UV-VIS and base peak chromatograms from LC/APCI-MS analysis of the sapropel acetone extracts can be divided into two basic types (A and $\mathrm{B}$ ) on the basis of the pigment distributions (see Figs. 3 and 4 for examples and Table 3 for major pigment assignments). Both types of UV-VIS chromatograms (Figs. 3A, 4A) showed a similar pigment distribution from 15 to 35 min (peaks 1-17). However, the type $\mathrm{B}$ distribution exhibited up to 25 additional pigment components at longer retention times (Fig. 3A), unlike type A (Fig. 4A). Seven of the samples showed the simpler type A distribution and the other 15 exhibited the more complex type B distribution (Table 1; Figs. 1, 2). The pigment distribution over one single sapropel layer is consistent, and the type A samples originate mostly from deep sapropel layers at Site 966 (Figs. 1, 2; Table 1). In lithologic Unit I of Hole 966D, many of the organic matter-rich sediment layers are bioturbated and show geochemical evidence of partial oxidation of the organic matter. However, there does not appear to be any obvious relationship between pigment distribution and the sedimentological parameters of the sapropels (organic carbon contents were not available for most of the samples).

\section{REFERENCES}

Kidd, R.B., Cita, M.B., and Ryan, W.B.F., 1978. Stratigraphy of eastern Mediterranean sapropel sequences recovered during DSDP Leg 42A and their paleoenvironmental significance. In Hsü, K.J., Montadert, L., et al., Init. Repts. DSDP, 42 (Pt. 1): Washington (U.S. Govt. Printing Office), 421-443.

Date of initial receipt: 22 November 1996

Date of acceptance: 22 June 1997

Ms 160SR-055 

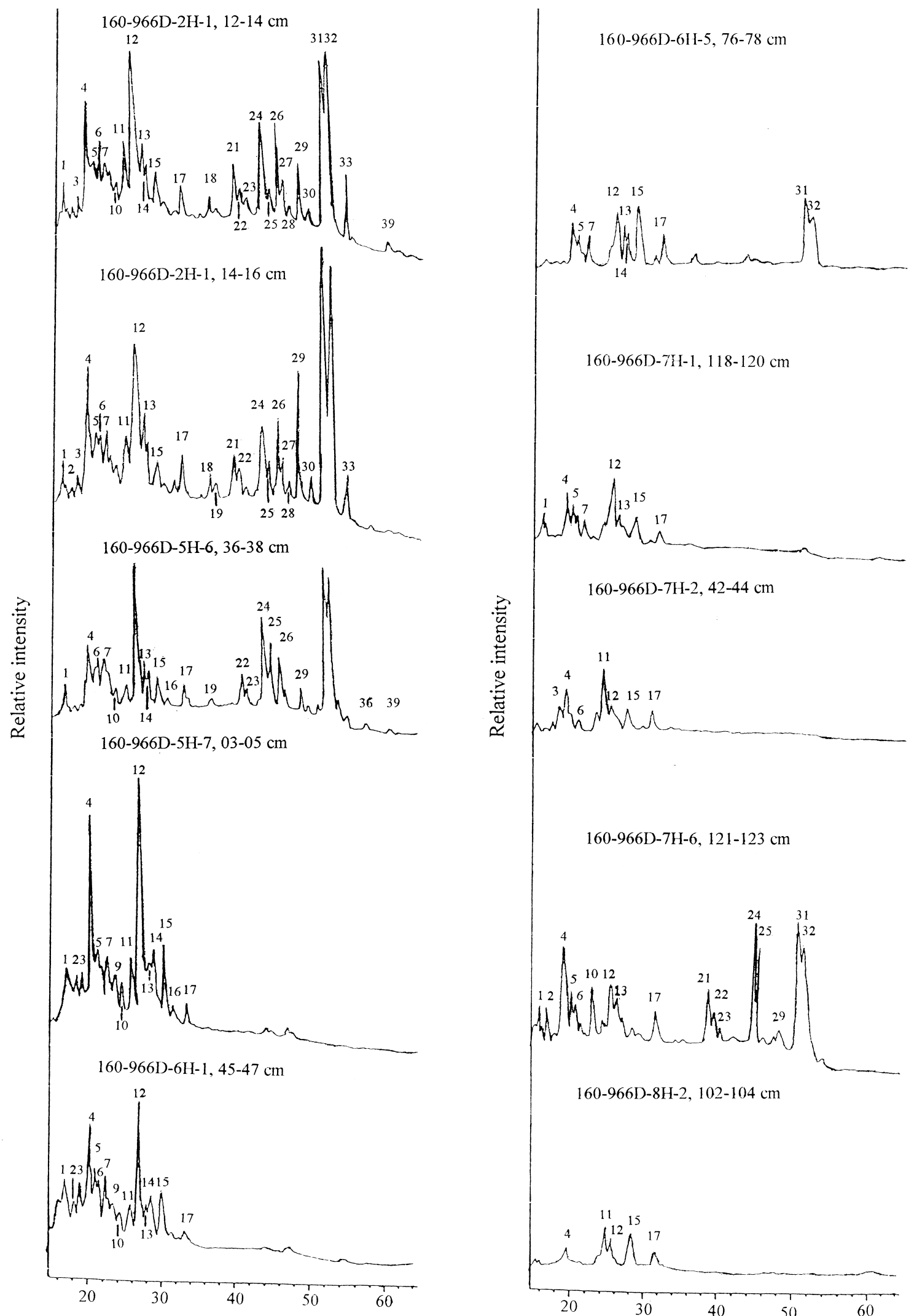

$160-966 \mathrm{D}-7 \mathrm{H}-1,118-120 \mathrm{~cm}$

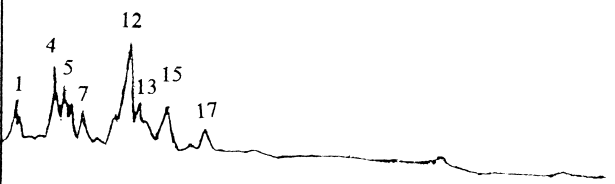

160-966D-7H-2, 42-44 cm

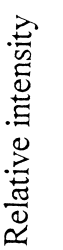

$160-966 \mathrm{D}-7 \mathrm{H}-6,121-123 \mathrm{~cm}$

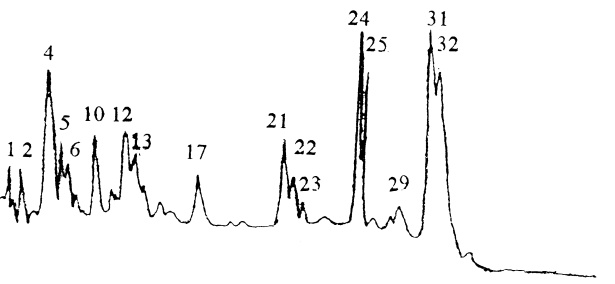

$160-966 \mathrm{D}-8 \mathrm{H}-2,102-104 \mathrm{~cm}$
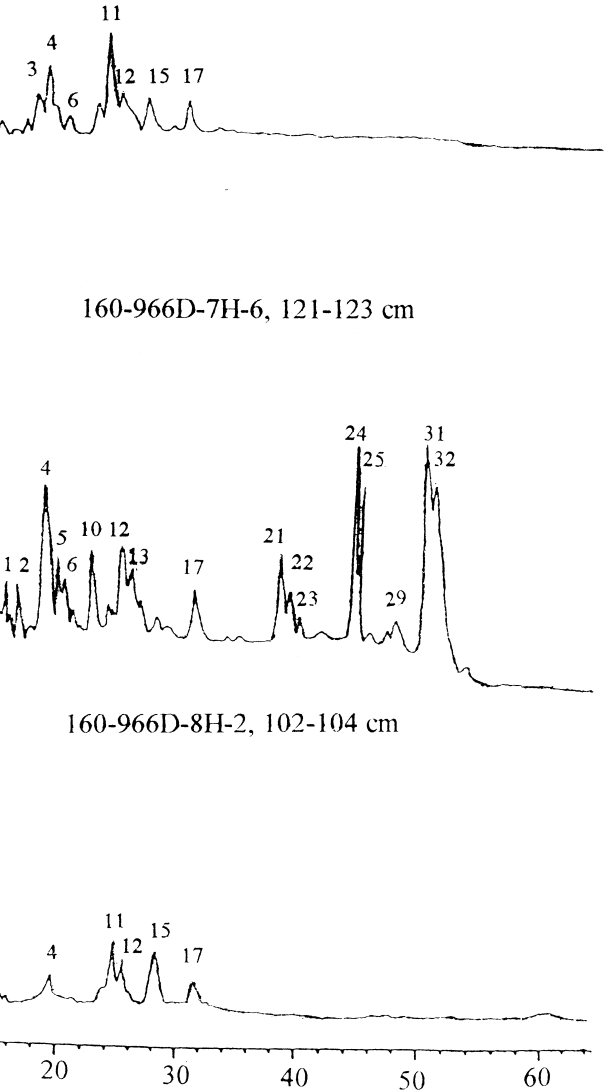

Elution time ( $\mathrm{min})$

Figure 1. Partial (15-65 min) UV-VIS $(\lambda=430 \mathrm{~nm})$ chromatograms of acetone extracts from Hole 966D samples, except Sample 160-966D-5H-7, 34-36 cm, presented in detail in Figure 4. For labeled peak identities, see Table 3. 


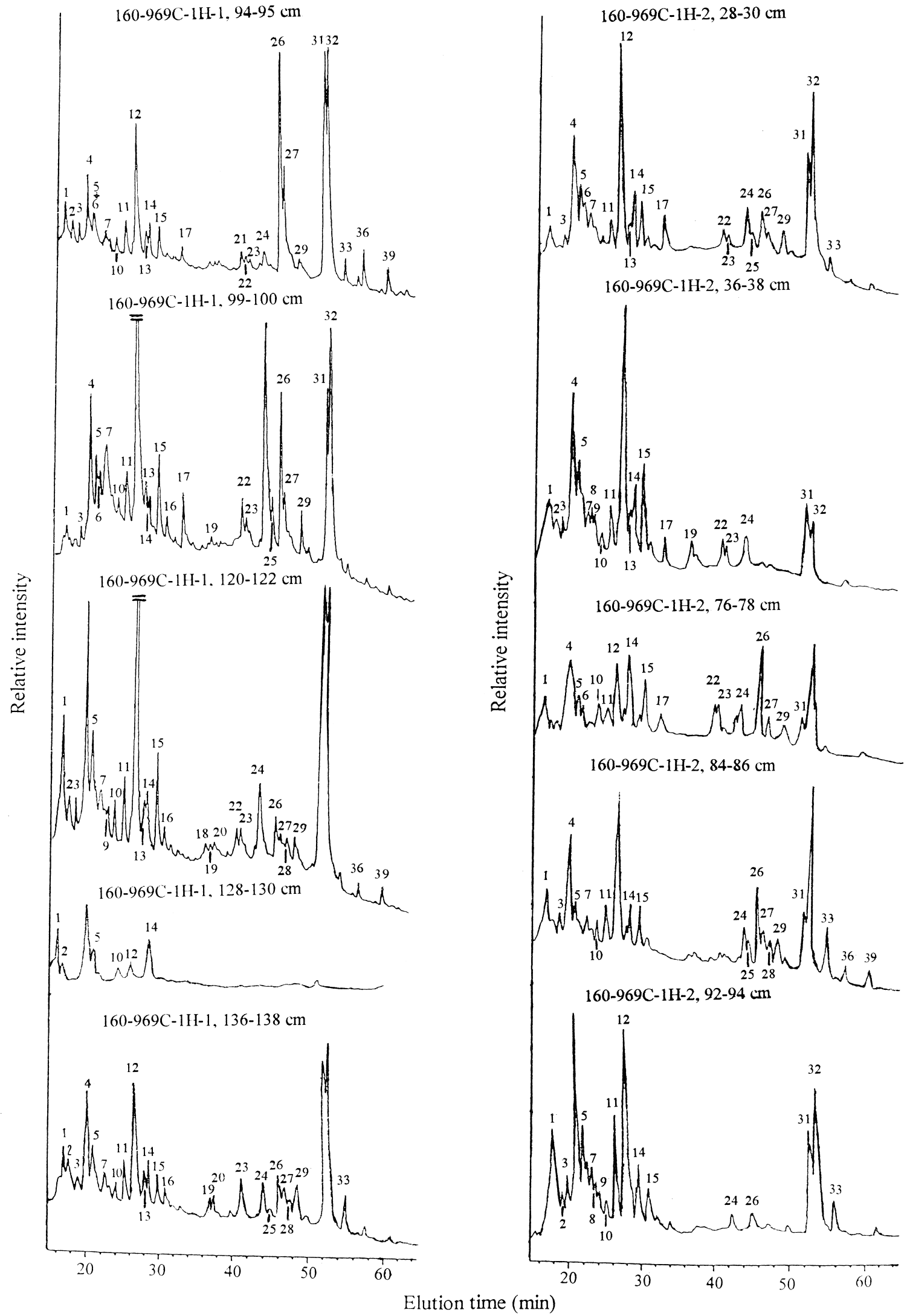

Figure 2. Partial (15-65 min) UV-VIS $(\lambda=430 \mathrm{~nm})$ chromatograms of acetone extracts from Hole 969C samples, except Sample 160-969C-1H-2, 32-34 cm, presented in detail in Figure 3. For labeled peak identities, see Table 3. 


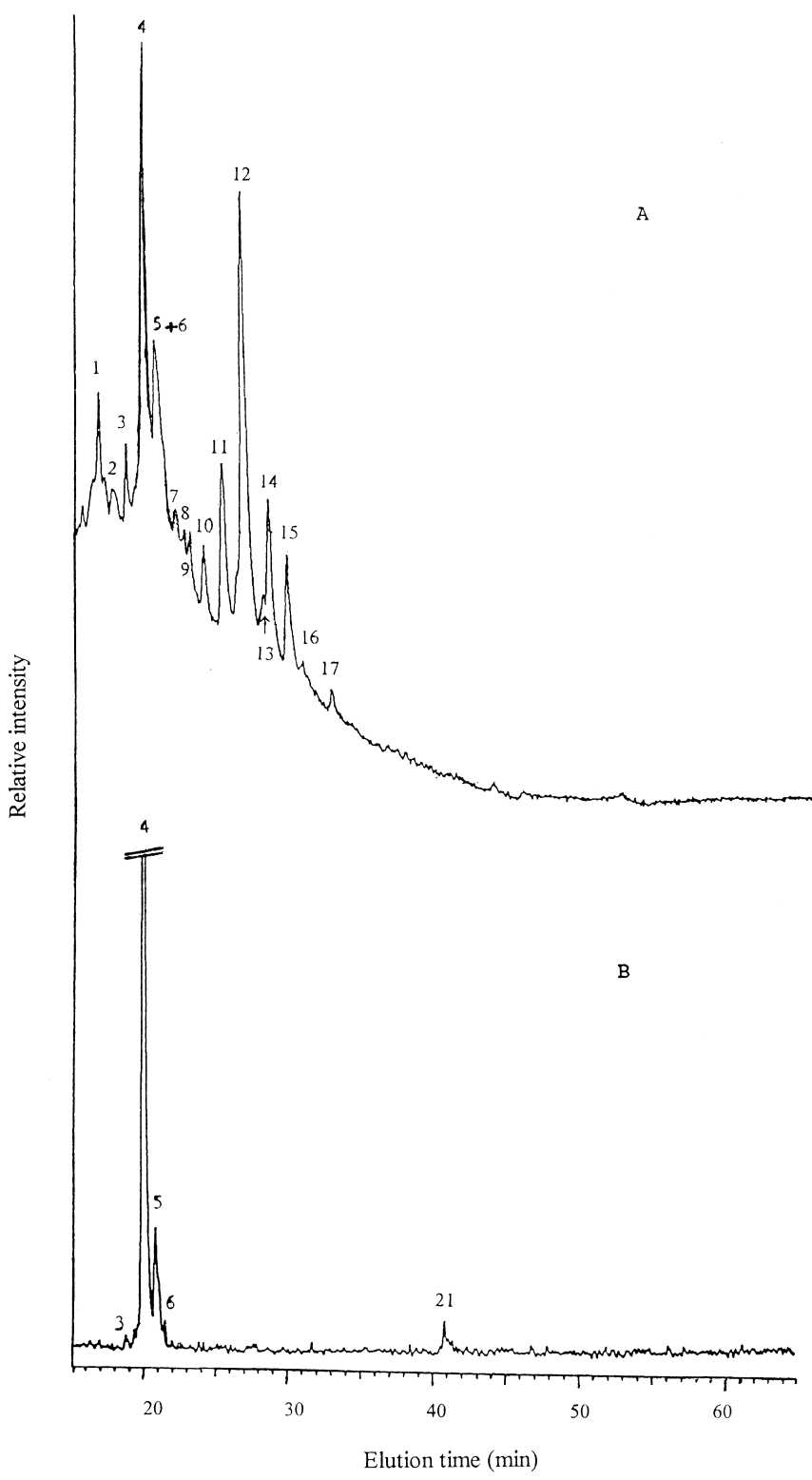

Figure 3. (A) Partial (15-65 min) UV-VIS $(\lambda=430 \mathrm{~nm})$ and (B) base peak ion chromatograms illustrating the type A pigment distribution. Chromatograms are from the positive-ion LC/APCI-MS analysis of the acetone extract from Sample 160-969C-1H-2, 32-34 cm. Peak identities are given in Table 3.

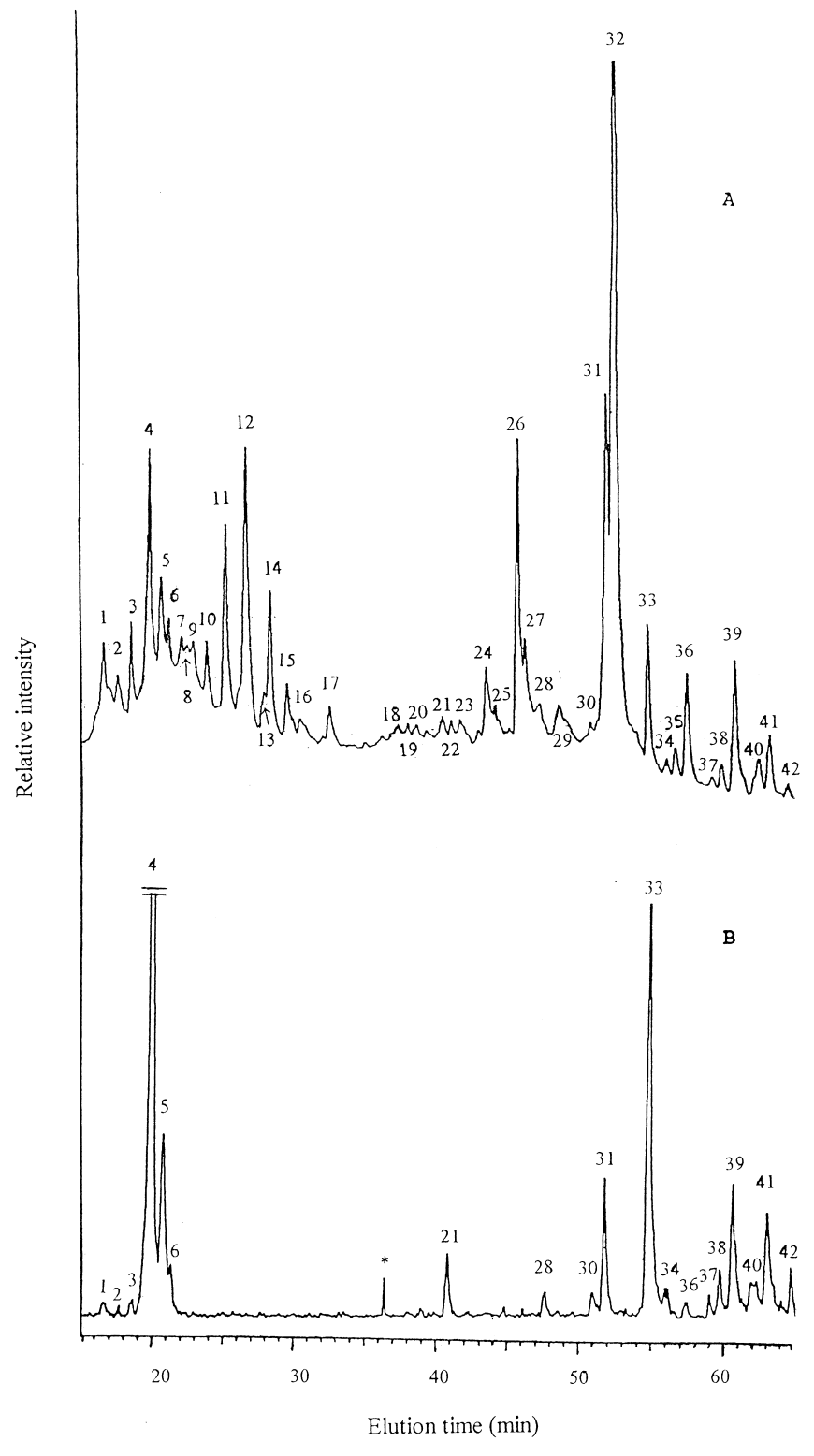

Figure 4. (A) Partial (15-65 min) UV-VIS $(\lambda=430 \mathrm{~nm})$ and (B) base peak ion chromatograms illustrating the type B pigment distribution. Chromatograms are from the positive-ion LC/APCI-MS analysis of the acetone extract from Sample 160-966D-5H-7, 34-36 cm. Peak identities are given in Table 3. * = unknown, nonpigment impurities. 
Table 3. Significant components in acetone extracts from sapropel samples identified by LC-MS analysis.

\begin{tabular}{|c|c|c|c|c|c|}
\hline Peak & $\mathrm{t}_{\mathrm{R}}(\min )$ & $\lambda_{\max }(\mathrm{nm})$ & {$[\mathrm{M}+\mathrm{H}]^{+*}$} & Prominent ions $\dagger$ & Assignment** \\
\hline 1 & 16.7 & $413-435-653$ & 549 & $529-503-475$ & Pyrophaeophorbide $b$ \\
\hline 2 & 17.8 & $413-435-653$ & 549 & $529-503-575$ & Pyrophaeophorbide $b$ isomer \\
\hline \multirow[t]{2}{*}{$3 \ddagger$} & 18.6 & $450-480-505$ & - & & Unidentified \\
\hline & & $406-500-535-603-663$ & 535 & $517-507-491$ & Pyrophaeophorbide $a$ \\
\hline 4 & 19.9 & $411-506-535-611-668$ & 533 & $515-505-489$ & Chlorophyllone $a$ \\
\hline 5 & 20.9 & $411-506-535-611-668$ & 533 & $515-505-489$ & Chlorophyllone $a$ epimer \\
\hline \multirow[t]{2}{*}{$6+$} & 21.4 & $400-503-535-615-670$ & 549 & 521 & Unknown Chl $a$ derivative \\
\hline & & $467-495-522$ & 565 & & Unidentified \\
\hline 7 & 22.1 & 480 & - & & Carotenoid \\
\hline 8 & 22.4 & $420-445-470$ & - & & Carotenoid \\
\hline 9 & 23.0 & $422-448-473$ & - & & Carotenoid \\
\hline 10 & 23.8 & $420-449-479$ & - & & Carotenoid \\
\hline 11 & 25.2 & $422-448-473$ & - & & Carotenoid \\
\hline 12 & 26.5 & $426-451-477$ & - & & Zeaxanthin? \\
\hline 13 & 27.8 & 560 & - & & Unidentified \\
\hline 14 & 28.3 & $423-450-475$ & - & & Carotenoid \\
\hline 15 & 29.6 & $421-445-473$ & - & & Carotenoid \\
\hline 16 & 30.4 & $418-441-472$ & - & & Carotenoid \\
\hline 17 & 32.5 & 475 & - & & Canthaxanthin? \\
\hline 18 & 36.7 & (355)-413-(442) & - & & Unidentified \\
\hline 19 & 37.7 & (355)-413-(422) & - & & Unidentified \\
\hline 20 & 38.1 & (355)-413-(422) & - & & Unidentified \\
\hline \multirow[t]{2}{*}{$21 \ddagger$} & 40.7 & $420-445-475$ & - & & Carotenoid \\
\hline & & $467-495-525$ & 538 & & Unidentified \\
\hline 22 & 41.2 & $420-447-475$ & - & & Carotenoid \\
\hline 23 & 41.7 & $415-442-472$ & - & & Carotenoid \\
\hline 24 & 43.5 & 485 & 551 & & Unidentified \\
\hline 25 & 44.0 & $408-507-535-610-669$ & - & & Chlorin \\
\hline 26 & 45.6 & $427-453-481$ & - & & Carotenoid \\
\hline 27 & 46.1 & $429-475-500$ & - & & Lycopene derivative? \\
\hline \multirow[t]{2}{*}{$28 \ddagger$} & 47.5 & $409-505-535-608-665$ & 887 & $609-559$ & Phaeophytin $a$ allomer \\
\hline & & 390 & 536 & & Unidentified \\
\hline 29 & 48.5 & $425-442-474$ & - & & Carotenoid \\
\hline 30 & 51.0 & $410-505-535-610-667$ & 871 & 593 & Phaeophytin $a$ \\
\hline \multirow[t]{2}{*}{$31 \ddagger$} & 51.8 & $413-435-653$ & 827 & 549 & Pyrophaeophytin $b$ \\
\hline & & $422-446-472$ & - & & $\alpha$-carotene \\
\hline 32 & 52.3 & $422-450-474$ & - & & $\beta$-carotene \\
\hline 33 & 54.8 & $410-505-535-610-667$ & 813 & 535 & Pyrophaeophytin $a$ \\
\hline 34 & 56.0 & $410-505-535-610-667$ & 813 & 535 & Pyrophaeophytin $a$ isomer \\
\hline 35 & 56.5 & $413-435-653$ & 915 & 549 & Steryl chlorin ester $b$ \\
\hline 36 & 57.3 & $413-435-653$ & 929 & 549 & Steryl chlorin ester $b$ \\
\hline 37 & 59.0 & $410-505-535-610-667$ & 887 & 535 & Steryl chlorin ester $a$ \\
\hline 38 & 59.8 & $410-505-535-610-667$ & 901 & 535 & Steryl chlorin ester $a$ \\
\hline $39 \ddagger$ & 60.5 & $410-505-535-610-667$ & 915,901 & 535 & Steryl chlorin esters $a$ \\
\hline $40 \%$ & 62.2 & $410-505-535-610-667$ & 915,929 & 535 & Steryl chlorin esters $a$ \\
\hline 41 & 63.3 & $410-505-535-610-667$ & 903 & 535 & Steryl chlorin ester $a$ \\
\hline $42 \ddagger$ & 65.0 & $410-505-535-610-667$ & $903,945,931$ & 535 & Steryl chlorin esters $a$ \\
\hline
\end{tabular}

Notes: $*=$ protonated molecule. $\dagger=$ other ions in mass spectrum. $* *=$ based on UV-VIS and mass spectral interpretation. $\neq=$ coelution. $-=$ not observed. 